\title{
A INFLUÊNCIA DA CONCENTRAÇÃO DE ACEROLA (MALPIGHIA, SSP.) NO TEOR DE VITAMINA C EM BEBIDA LÁCTEA ADICIONADA DE FARINHA DE LINHAÇA DOURADA (LINUM USITATISSIMUM L.).
}

\author{
B. SILVA ${ }^{1}$, M. T. BARCIA ${ }^{2}$, P. N. da CRUZ ${ }^{3}$ e P. B. PERTUZATTI ${ }^{4}$ \\ ${ }^{1}$ Universidade Federal do Rio Grande, Escola de Química e Alimentos \\ ${ }^{2}$ Universidade Estadual de Campinas, Departamento de Ciência de Alimentos \\ ${ }^{3}$ Universidade Federal de Santa Catarina, Departamento de Engenharia Química e Engenharia de \\ Alimentos \\ ${ }^{4}$ Universidade Federal de Mato Grosso, Instituto de Ciências Exatas e da Terra \\ E-mail para contato: bibianaengenheira@hotmail.com
}

\begin{abstract}
RESUMO - Bebidas lácteas são produtos à base de soro de leite, podendo ser adicionadas de corantes, aromatizantes, entre outros aditivos. A acerola é um fruto tropical de potencial econômico e nutricional que possui altos teores de ácido ascórbico (vitamina C), conhecido por suas propriedades antioxidantes; de grande capacidade de aproveitamento industrial, como na formulação de bebidas lácteas. Neste experimento foi realizado um delineamento composto central rotacional (DCCR), resultando em onze ensaios de bebida láctea com diferentes proporções de farinha de linhaça e polpa de acerola. As concentrações iniciais de acerola e linhaça nos ensaios foram definidas por testes, e foram respectivamente em massa: $1(25 \mathrm{e}$ 6)\%; 2 (35 e 6)\%; 3 (25 e 10)\%; 4 (35 e 10)\%; 5 (22,95 е 8)\%; 6 (37,05 е 8)\%; 7 (30 e 5,18)\%; 8 (30 e 10,82)\% e 9, 10 e 11 (30 e 8)\%. Foi analisado o teor de vitamina C dos ensaios. Os resultados mostraram que não houve perda de vitamina $\mathrm{C}$ nas bebidas lácteas durante o processamento, e a farinha de linhaça interferiu negativamente no teor deste composto, implicando que os ensaios com maiores concentrações de polpa de acerola não resultaram em maiores teores do composto, pois a linhaça interferiu na redução do teor. Quanto maior a concentração da polpa, maior foi a interação com a linhaça e menor o teor de vitamina $\mathrm{C}$. $\mathrm{O}$ ensaio 2 se mostrou uma opção, por possuir grande quantidade de acerola e pequena quantidade de linhaça, diminuindo a interferência, e consequentemente aumentando a disponibilidade da vitamina $\mathrm{C}$.
\end{abstract}

\section{INTRODUÇÃO}

Alimentos funcionais são aqueles que, além de contribuírem com a nutrição, contêm substâncias que podem ser consideradas biologicamente ativas, produtoras de benefícios clínicos ou de saúde. (Komatsu, 2008). Têm sido lançados no mercado diversos novos produtos, sendo 
que, especificamente na área de laticínios, ênfase tem sido dada ao desenvolvimento de produtos funcionais. (Kempka et al., 2008)

Dentro dessa classe de alimentos, encontram-se os derivados lácteos fermentados, destacando-se as bebidas lácteas, produzidas basicamente a partir da adição de leite bovino e soro de leite, proveniente da fabricação de queijos, em proporções adequadas. Formulações de bebidas lácteas a base de frutas caracterizam o produto como atrativo ao consumidor, pois as tornam mais saborosas e nutritivas.

Além de agregar valor, visto sua riqueza em nutrientes, a adição de sabores de frutas configura como um dos fatores primordiais para a obtenção de um produto com sabor agradável e que venha a melhorar a sua aceitação pelo consumidor. (Oliveira, 2009). Existe no mercado uma gama de bebidas lácteas dos mais variados sabores, as mais comuns são as adicionadas de polpa de frutas. (Matos, 2009).

Por sua grande capacidade de aproveitamento industrial, a acerola tem atraído o interesse dos fruticultores de várias regiões do Brasil. A adição de polpa de acerola à bebida láctea é uma opção interessante, visto a significativa produção deste fruto no país, seu elevado conteúdo de vitamina C (2.500 a 4.500mg/100g) (Nogueira et al., 2002) e considerável teor de carotenoides e compostos fenólicos, além de sua boa aceitação e consumo. (Costa, 2003; Moreira, 2007).

Não é comum a fabricação de bebida láctea utilizando apenas a acerola. Geralmente encontram-se misturas de sabores, contendo além de acerola, outras frutas. Porém o desenvolvimento de uma formulação contendo apenas polpa de acerola pode dar a dimensão da quantidade de vitamina $\mathrm{C}$ que esse fruto pode fornecer ao produto final.

O trabalho teve como objetivo o desenvolvimento de formulações de bebida láctea fermentada, com polpa de acerola e farinha de linhaça dourada, utilizando um planejamento experimental, avaliando-se o teor de vitamina $\mathrm{C}$ e os efeitos do processamento.

\section{MATERIAIS E MÉTODOS}

\subsection{Formulação do experimento}

A formulação utilizada neste trabalho foi composta pelos seguintes ingredientes: açúcar, leite e soro de leite, e as combinações de acerola e linhaça (em porcentagem base leite) acrescentadas à formulação de acordo com um delineamento composto central rotacional (DCCR). A tabela 1 apresenta os onze ensaios estudados em valores reais e codificados.

Tabela 1 - Matriz do planejamento experimental para a adição das diferentes concentrações de polpa de acerola e farinha de linhaça dourada na formulação das bebidas lácteas

\begin{tabular}{ccc}
\hline Ensaios & $\begin{array}{c}\text { Níveis codificados das variáveis } \\
\text { independentes }\end{array}$ & $\begin{array}{c}\text { Níveis não-codificados das } \\
\text { variáveis independentes }\end{array}$ \\
\hline
\end{tabular}




\begin{tabular}{|c|c|c|c|c|}
\hline & $\mathrm{X}_{1}$ & $\mathrm{X}_{2}$ & Acerola $(\%)$ & Linhaça $(\%)$ \\
\hline \multicolumn{5}{|c|}{$\begin{array}{l}\text { Porção } \\
\text { fatorial }\end{array}$} \\
\hline 1 & -1 & -1 & 25 & 6 \\
\hline 2 & 1 & -1 & 35 & 6 \\
\hline 3 & -1 & 1 & 25 & 10 \\
\hline 4 & 1 & 1 & 35 & 10 \\
\hline \multicolumn{5}{|c|}{ Pontos axiais } \\
\hline 5 & $-1,41$ & 0 & 22,95 & 8 \\
\hline 6 & 1,41 & 0 & 37,05 & 8 \\
\hline 7 & 0 & $-1,41$ & 30 & 5,18 \\
\hline 8 & 0 & 1,41 & 30 & 10,82 \\
\hline \multicolumn{5}{|c|}{$\begin{array}{l}\text { Pontos } \\
\text { centrais }\end{array}$} \\
\hline 9 & 0 & 0 & 30 & 8 \\
\hline 10 & 0 & 0 & 30 & 8 \\
\hline 11 & 0 & 0 & 30 & 8 \\
\hline
\end{tabular}

O soro de leite foi submetido a um processo de pasteurização lenta em banho-maria, a $65^{\circ}$ C por 30 min. Em seguida, o leite UHT, o soro de leite pasteurizado e o açúcar cristal foram aquecidos em banho-maria a uma temperatura de 40 a $45^{\circ} \mathrm{C}$ aproximadamente. $\mathrm{O}$ fermento láctico (Lactobacillus Bulgaricus e Streptococcus Thermophilus) foi adicionado e a mistura foi incubada, a $42^{\circ} \mathrm{C}$ e o processo de fermentação se deu até o pH atingir entre 4,6 e 5,2. (Dias, 2008).

Após, foram adicionadas a polpa de acerola e a farinha de linhaça dourada, e foi feita a homogeneização do produto. $\mathrm{O}$ mesmo foi embalado em garrafas plásticas estéreis e refrigerado a $5^{\circ} \mathrm{C}$, em incubadora do tipo BOD (Biologic Oxygen Demand).

\subsection{Determinação de ácido ascórbico}


A determinação de ácido ascórbico foi realizada de acordo com o método adaptado de Strohecker-Henning (1967), que consiste na redução do 2,6 diclorofenol-indofenol-sódio (DFI) pelo ácido ascórbico. O DFI em meio básico é azul, em meio ácido é rosa e sua forma reduzida é incolor. O ponto final da titulação é detectado pela viragem da solução de incolor para rosa, quando a primeira gota de solução de DFI é introduzida no sistema, com todo o ácido ascórbico já consumido. Foram pesados $1 \mathrm{~g}$ de amostra e $50 \mathrm{~mL}$ da solução de ácido oxálico a $0,5 \%$, e completado o volume de $100 \mathrm{~mL}$ com água destilada em balão volumétrico. Titulou-se com a solução de 2,6 diclorofenol indofenol - sódio até coloração rosa persistente por $15 \mathrm{~s}$. O resultado foi expresso em mg de ácido ascórbico por $100 \mathrm{~mL}$ da amostra, conforme a equação 1.

$$
\text { Ácido ascórbico }\left(\frac{m g}{100 m L}\right)=\frac{100 \times n}{N / 5 \times V}
$$

$\mathrm{n}=$ número de $\mathrm{mL}$ de 2,6 diclorofenol indofenol - sódio, gastos na titulação da amostra

$\mathrm{V}=$ volume de amostra usado na titulação

$\mathrm{N}$ = número de $\mathrm{mL}$ de 2,6 diclorofenol indofenol - sódio, gastos na padronização

\subsection{Análise estatística}

Os dados obtidos foram avaliados pela análise de variância (ANOVA), utilizando o software Statistic for Windows 7.0, a fim de verificar a significância estatística das diferenças entre as amostras ao nível de significância de $5 \%$.

\section{RESULTADOS E DISCUSSÕES}

Os valores médios de ácido ascórbico dos ensaios se encontram na Tabela 2 abaixo.

Tabela 2- Valores médios de ácido ascórbico em polpa de acerola e em bebidas lácteas

\begin{tabular}{cccc}
\hline \multirow{2}{*}{ Ensaios } & Acerola & Linhaça & $\begin{array}{c}\text { Ácido ascórbico } \\
(\mathbf{m g} / \mathbf{1 0 0 g})\end{array}$ \\
\cline { 2 - 3 } & \multicolumn{2}{c}{ Níveis reais } & \\
\hline 1 & 25 & 6 & 333,24 \\
2 & 35 & 6 & 577,43 \\
3 & 25 & 10 & 271,74 \\
4 & 35 & 10 & 449,58 \\
5 & 22,95 & 8 & 290,94 \\
6 & 37,05 & 8 & 472,56 \\
7 & 30 & 5,18 & 440,89 \\
8 & 30 & 10,82 & 390,56 \\
9 & 30 & 8 & 300,27 \\
10 & 30 & 8 & 305,50 \\
\hline
\end{tabular}




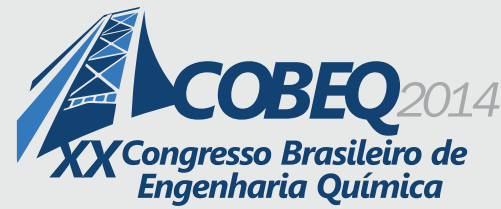

19 a 22 de outubro de 2014

Florianópolis/SC

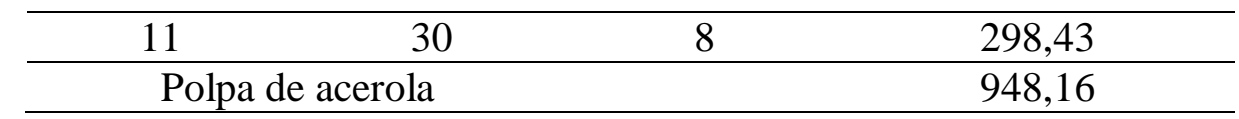

O valor médio de ácido ascórbico encontrado na polpa de acerola foi de 948,16 $\mathrm{mg} / 100 \mathrm{mg}$ de polpa. O teor está de acordo com o exigido pelo Padrão de Identidade e Qualidade para polpa de acerola (Brasil, 2000), que estabelece um valor mínimo de $800 \mathrm{mg}$ ácido ascórbico/100g de polpa.

Neves (2009) encontrou valores semelhantes em polpa de acerola, de aproximadamente 900 $\mathrm{mg} / 100 \mathrm{~g}$, porém com adição de própolis na polpa. Oliveira et al., (2009) encontraram em média aproximadamente $990 \mathrm{mg} / 100 \mathrm{~g}$ de ácido ascórbico em polpa de acerola. Já Sebastiany et al., (2009) encontrou valores próximos de $1100 \mathrm{mg} / 100 \mathrm{~g}$ em polpa pasteurizada, após 45 dias de armazenamento, sendo o prazo de validade da polpa de acerola de doze meses. $\mathrm{O}$ autor, em seu estudo, verificou que o armazenamento provoca perdas de ácido ascórbico em polpas congeladas.

A tabela de valores médios (Tabela 2) mostra que ensaios com a mesma quantidade de polpa de acerola apresentaram diferentes quantidades de vitamina $\mathrm{C}$. Tal fato pode ser explicado observando a Tabela 3, com os coeficientes de regressão, que aponta que todas as variáveis em questão foram significativas $(\mathrm{p}<0,05)$ para este método; a variável linear da linhaça apresentou interferência negativa quanto ao teor de vitamina $\mathrm{C}$ e a variável quadrática apresentou efeito positivo.

Assim quanto maior o teor de farinha de linhaça dourada, em ensaios com iguais quantidades de polpa de acerola, menores foram os níveis de vitamina $\mathrm{C}$, fato que pode ser observado comparando o ensaio 8 (ponto axial $+1,41=10,82 \%$ farinha de linhaça) com $390,56 \mathrm{mg} / 100 \mathrm{~g}$ produto de vitamina $\mathrm{C}$ com o ensaio 7 (ponto axial $-1,41=5,18 \%$ farinha linhaça) que teve o teor de vitamina $C$ de $440,89 \mathrm{mg} / 100 \mathrm{~g}$ produto. Porém, conforme o observado no coeficiente de regressão da linhaça quadrática, o efeito positivo gera valores de vitamina $\mathrm{C}$ nos pontos centrais menores (média $301,40 \mathrm{mg} / 100 \mathrm{~g}$ produto) do que no ensaio 8 que trabalhou-se com maior teor de farinha linhaça .

Tabela 3- Coeficientes para resultados de ácido ascórbico em bebidas lácteas

\begin{tabular}{cclcc}
\hline & $\begin{array}{c}\text { Coeficientes de } \\
\text { regressão }\end{array}$ & Erro padrão & t calculado & p-valor \\
\hline Média & 301,400 & 18,893 & 15,952 & \\
Acerola $(\mathbf{L})$ & $\mathbf{8 4 , 8 5 9}$ & $\mathbf{1 1 , 5 6 9}$ & $\mathbf{7 , 3 3 4}$ & $<0.001$ \\
Acerola $(\mathbf{Q})$ & $\mathbf{4 2 , 4 9 0}$ & $\mathbf{1 3 , 7 7 1}$ & $\mathbf{3 , 0 8 5}$ & $\mathbf{0 . 0 0 1}$ \\
Linhaça (L) & $\mathbf{- 3 2 , 5 6 6}$ & $\mathbf{1 1 , 5 6 9}$ & $\mathbf{- 2 , 8 1 5}$ & $\mathbf{0 , 0 3 7}$ \\
Linhaça(Q) & $\mathbf{5 8 , 4 7 7}$ & $\mathbf{1 3 , 7 7 1}$ & $\mathbf{4 , 3 1 9}$ & $\mathbf{0 , 0 0 7}$ \\
1L x 2L & $-16,587$ & 16,362 & $-1,014$ & 0,357 \\
\hline
\end{tabular}


Observa-se que o fator linear da acerola foi o que apresentou maior influência na quantidade de vitamina $\mathrm{C}$ das bebidas lácteas, o que era esperado, visto a significativa quantidade de ácido ascórbico presente na acerola (Lima, 2010).

$$
Y=301,4+84,85 X_{1}+42,49 X_{2}^{2}-32,56 X_{2}+42,49 X_{2}^{2}(2)
$$

$\mathrm{X}_{1}=$ Porcentagem de acerola

$\mathrm{X}_{2}=$ Porcentagem de linhaça

A ANOVA (Tabela 4) para o modelo de vitamina $\mathrm{C}$ apresenta uma variação explicada de 94,4\%, sendo possível gerar superfície de resposta para deste parâmetro, conforme a Figura 1 abaixo.

Tabela 4 - ANOVA para resultados de vitamina $\mathrm{C}$ em bebidas lácteas.

\begin{tabular}{cccccc}
\hline $\begin{array}{c}\text { Fontes de } \\
\text { variação }\end{array}$ & $\begin{array}{c}\text { Soma dos } \\
\text { quadrados }\end{array}$ & $\begin{array}{c}\text { Graus de } \\
\text { liberdade }\end{array}$ & $\begin{array}{c}\text { Quadrado } \\
\text { médio }\end{array}$ & F calculado & F tabelado \\
\hline Regressão & 89933,45 & 4 & 22483,36 & 20,90 & 4,53 \\
Resíduos & 6455,16 & 6 & 1075,06 & & \\
Erro puro & 26,91 & 2 & 13,45 & & \\
Total & 96388,61 & 10 & & & \\
\hline
\end{tabular}

Nível de significância $\alpha=0,05 ; \mathrm{R}^{2}: 94,4 \%$

Figura 1- Superfície de resposta de vitamina $\mathrm{C}$ em bebidas lácteas.

Vitamina C

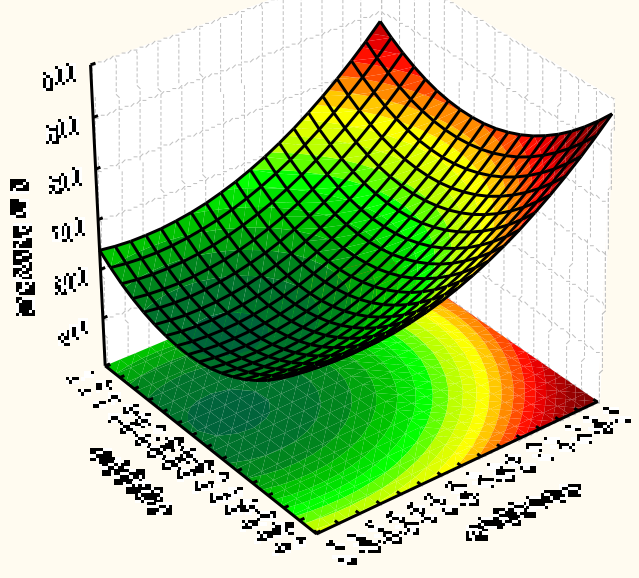


A superfície representa visivelmente a interação da polpa de acerola com a farinha de linhaça dourada, mostrando o ponto mais alto do gráfico, que representa o maior teor de vitamina $\mathrm{C}$, no qual a concentração de acerola é a maior e a de linhaça a menor.

Para a análise de perda de vitamina $C$ nos ensaios, foi feita uma relação dos teores de vitamina $\mathrm{C}$ dos mesmos com os teores presentes na quantidade de polpa de acerola adicionada em cada um deles.

Com relação a perdas de vitamina $\mathrm{C}$ nas bebidas lácteas, apesar da interferência negativa da linhaça, os ensaios não apresentaram redução dos teores de vitamina $C$ com relação aos teores encontrados para a quantidade de polpa de acerola adicionada em cada um. A interferência positiva do efeito quadrático da linhaça pode explicar isso, sendo levado em consideração que este efeito pode gerar um aumento do teor de vitamina $\mathrm{C}$ dos ensaios com relação ao teor de vitamina $\mathrm{C}$ referente à quantidade de polpa de acerola adicionada em cada um deles.

Macêdo et al., (2011) verificou a quantidade de vitamina C presente em bebida láctea de maracujá $(29,66 \mathrm{mg} / 100 \mathrm{~g})$, e observou que a perda foi mínima, com a relação a quantidade presente na polpa da fruta $(30 \mathrm{mg} / 100 \mathrm{~g})$, pois não houveram interferências, somente pequenas perdas por volatilidade.

Santa Rosa, (2011), afirma que dados de vitamina C em derivados lácteos são escassos, e em seu trabalho, produziu iogurtes a partir de leite de búfala, de acerola, bacuri e cupuaçu, registrando maiores teores de vitamina $\mathrm{C}$ na formulação com polpa de acerola, em torno de $210,40 \mathrm{mg} / 100 \mathrm{~g}$.

\section{CONCLUSÃO}

O teor de vitamina $\mathrm{C}$ da polpa utilizada estava de acordo com o exigido pela legislação vigente e não houve perdas no processamento das bebidas lácteas. $\mathrm{O}$ ensaio 2 se mostrou uma boa opção, com relação ao teor de vitamina $C$, por possuir grande quantidade de polpa de acerola e pequena quantidade de farinha de linhaça dourada, diminuindo a interferência com relação ao parâmetro, e consequentemente aumentando a disponibilidade da vitamina.

\section{REFERÊNCIAS}

BRASIL. Ministério da Agricultura Pecuária e Abastecimento. Instrução Normativa n॰16, de 23 de agosto de 2005. Regulamento técnico para fixação dos padrões de identidade e qualidade para polpa de acerola. Diário Oficial da União, Brasília - DF, 2000.

COSTA, T. S. A.; ABREU, L. N.; ROSSETTI, A. G. Efeito do congelamento e do tempo de estocagem da polpa de acerola sobre o teor de carotenoides. Revista Brasileira de Fruticultura. Jaboticabal - SP, v. 25, p. 56-58, 2003.

DIAS, M. C. Utilização de diferentes substratos e culturas comerciais empregadas na produção de bebidas lácteas. Piracicaba - SP, p. 38, 2008. 
KEMPKA, A. P.; KRÜGER, R. L.; VALDUGA, E.; LUCCIO, M. D.; TREICHEL, H.;

CANSIAN, R.; OLIVEIRA, D. Formulação de bebida láctea fermentada sabor pêssego utilizando substratos alternativos e cultura probiótica. Ciência e Tecnologia de Alimentos, Campinas - SP, p. 170, 2008.

KOMATSU, T. R.; BURITI, F. C. A.; SAAD, S. M. I. Inovação, persistência e criatividade superando barreiras no desenvolvimento de alimentos probióticos. Revista Brasileira de Ciências Farmacêuticas, p. 329, 2008.

MACÊDO, W. V. L. ABREU, L. P.; SISNANDO, I. M. P.; SILVA, J. N. Avaliação físicoquímica de bebida láctea fermentada sabor maracujá (Passiflora edulis). Cariri-CE, p 28, 2001.

MATOS, R. A. Desenvolvimento e Mapa de Preferência Externo de bebida láctea a base de soro e polpa de graviola (Annona muricata). Itapetinga - BA, p. 22-30, 2009.

MOREIRA, G. E. G. Obtenção e caracterização de extrato microencapsulado de resíduo agroindustrial de acerola. Natal-RN, p. 6, 2007.

NEVES, M. V. M. Polpa de acerola (Malpighia emarginata D.C.) adicionada de extrato comercial de própolis: avaliação físico-química e sensorial. Recife - PE, p. 89, 2009

NOGUEIRA, R. J. M. C.; MORAES, J. A. P. V. M.; BURITY, H. A.; JUNIOR, J. F. J. Efeito do estádio de maturação dos frutos nas características físico-químicas de acerola. Brasília - DF, p. 2, 2002.

OLIVEIRA, M. E. G. Desenvolvimento de formulações de bebidas lácteas fermentadas a partir de soro e leite de cabra. João Pessoa - PB, p. 16-30, 2009.

SANTA ROSA, R. M. S. Iogurte de leite de búfala adicionado de polpa de frutas da amazônia: parâmetros de qualidade. Niterói - RJ, p. 33, 2011.

SEBASTIANY, E.; MOURA, E. R.; RÊGO, E. R.; VITAL, M. J. S. perda de vitamina c durante o armazenamento de polpa de acerola congelada. B. CEPPA. Curitiba - PR, p. 284, 2009.

STROHECKER, R.; HENNING, H. M. Analisis de vitaminas: métodos comprobados. Madrid: Paz Montalvo, p. 438, 1967. 